\title{
Effects of reduction time on the structural, electrical and thermal properties of synthesized reduced graphene oxide nanosheets
}

\author{
MOHAMAD FAHRUL RADZI HANIFAH ${ }^{1,2}$, JUHANA JAAFAR ${ }^{1, *}$, MADZLAN AZIZ ${ }^{2}$, \\ A F ISMAIL ${ }^{1}$, M H D OTHMAN ${ }^{1}$ and MUKHLIS A RAHMAN ${ }^{1}$ \\ ${ }^{1}$ Advanced Membrane Technology Research Centre (AMTEC), Faculty of Petroleum and Renewable Energy \\ Engineering, Universiti Teknologi Malaysia, 81310 UTM Skudai, Johor, Malaysia \\ ${ }^{2}$ Department of Chemistry, Faculty of Science, Universiti Teknologi Malaysia, 81310 UTM Skudai, Johor, Malaysia
}

MS received 6 February 2015; accepted 17 June 2015

\begin{abstract}
The reduction of graphene oxide (GO) nanosheet is a promising route to produce a stable colloidal dispersion of reduced graphene oxide (RGO) nanosheets in a large scale. The production of RGO nanosheet is one of the important topics in nanotechnology disciplines due to its contribution in various applications, such as the platinum catalyst support in direct methanol fuel cell. Therefore, in this paper, the RGO nanosheets were prepared via highly efficient chemical reduction reaction of exfoliated GO nanosheets using sodium oxalate $\left(\mathrm{Na}_{2} \mathrm{C}_{2} \mathrm{O}_{4}\right)$ as the reducing agent. Extensive characterizations have been conducted in terms of structural, thermal stability and electrical conductivity properties by means of high-resolution transmission microscopy, the Fourier transform infrared spectroscopy, UV-visible spectroscopy, ${ }^{13} \mathrm{C}$ NMR and four-point probe conductivity measurement. The results indicate that most of oxygen-containing functional groups from GO nanosheets have been removed and the RGO-3 possess greater thermal stability compared to GO nanosheets. The prepared RGO-3 shows the highest electrical conductivity at room temperature which is $\sim 2.0 \times 10^{3} \mathrm{~S} \mathrm{~m}^{-1}$. Based on these analyses, the plausible mechanism of reduction of GO to RGO by sodium oxalate is well proposed.
\end{abstract}

Keywords. Reduced graphene oxide nanosheets; graphene oxide nanosheets; sodium oxalate; thermal stability; electrical conductivity.

\section{Introduction}

Direct methanol fuel cell (DMFC) is an energy conversion system that has greater attraction as power sources for electronic device applications. Most of the researchers come with new ideas which focus to enhance the fuel cell's performance and reduce the cost. ${ }^{1}$ However, this has been delayed due to the deficiency of catalyst materials. Platinum $(\mathrm{Pt})$ is the most efficient electro-catalyst mainly chosen in fuel cell's application due to its highest catalytic activities compared to the other catalyst. ${ }^{2}$ However, the usage of Pt limits the practical application due to its expensive and less availability in nature. ${ }^{3}$ These limitations can be resolved by reducing the Pt loading at the electrodes with the use of electrocatalyst support. ${ }^{4}$ The characteristics of good material for electro-catalyst support are it should possess high electrical conductivity, good catalyst interaction and large surface area for high dispersion of Pt catalyst. In recent times, carbonaceous materials were greatly utilized as electro-catalyst support because carbon is an important electrode assembling for maximizing DMFC performance. ${ }^{5}$

Graphene is one of the most promising carbonaceous materials with two-dimensional layer of $\mathrm{sp}^{2}$ hybridized carbon atom that are arranged in a honeycomb lattice structure. ${ }^{6}$

\footnotetext{
*Author for correspondence (juhana@ petroleum.utm.my)
}

In recent years, it has received a rising attention in fuel cell research fields and been an important material as it possesses larger specific area, ${ }^{7}$ good mechanical strength,${ }^{8}$ higher electrical conductivity ${ }^{9}$ and excellent thermal stability. ${ }^{10}$ The large-scale production with low cost of producing graphene by the chemical reduction method has been considered to be the most appropriate approach. ${ }^{6,11}$ In recent times, the uses of environment-friendly reducing agents to produce reduced graphene oxide (RGO) nanosheets have been reported, such as pyrrole, ${ }^{12}$ L-glutathione, ${ }^{13}$ sodium diphenylamine sulphonate ${ }^{14}$ and ascorbic acid. ${ }^{15}$ However, its feasibility still requires further evaluations due to some of its drawbacks, such as high in cost, experimentally time consuming and limited applications. ${ }^{16}$

In our previous report, it was possible to synthesize graphene nanosheets just via reducing the GO nanosheets by sodium oxalate under heating treatment, which showed satisfying properties as demonstrated via efficient characterizations such as X-ray diffraction (XRD), X-ray photoelectron spectroscopy (XPS), high-resolution transmission electron microscopy (HRTEM) and Raman spectrometry. ${ }^{17}$ It was demonstrated that sodium oxalate could reduce the oxygencontaining functional groups, such as epoxy, hydroxyl, carboxyl and carbonyl groups on the surface and at the edge of GO. The outstanding advantage of using sodium oxalate is its high reducibility and less hazardous compared with vigorous 
and poison reducing agents such as hydrazine and sodium borohydride. Therefore, herein, the RGO nanosheets were prepared via chemical reduction of exfoliated GO by sodium oxalate as the efficient reducing agent. The structural, electrical conductivity and thermal stability of the prepared RGO were investigated.

\section{Experimental}

\subsection{Materials}

Purified graphite powder was obtained from Superior Graphite Co. Ltd. Sodium oxalate $\left(\mathrm{Na}_{2} \mathrm{C}_{2} \mathrm{O}_{4}\right)$ (Fisher brand), hydrogen peroxide $\left(\mathrm{H}_{2} \mathrm{O}_{2}, 35 \%\right)$ and sodium nitrate $\left(\mathrm{NaNO}_{3}\right)$ were purchased from Riedel-de Haën. Hydrochloric acid $(\mathrm{HCl}, 37 \%)$ was purchased from RCI Labscan, potassium permanganate $\left(\mathrm{KMnO}_{4}\right)$ from COMAK, and concentrated sulphuric acid $\left(\mathrm{H}_{2} \mathrm{SO}_{4}, 95-97 \%\right)$ from QRëC. All chemicals were of analytical grade and used as-received without further purification.

\subsection{Synthesis of GO nanosheets}

The GO nanosheet was synthesized through the oxidation of the purified graphite powder via modified Hummers' method. ${ }^{18}$ Three grams of $\mathrm{NaNO}_{3}$ was dissolved in $140 \mathrm{ml}$ of concentrated $\mathrm{H}_{2} \mathrm{SO}_{4}$ in an ice bath. Then, $15 \mathrm{~g}$ of $\mathrm{KMnO}_{4}$ and $3 \mathrm{~g}$ of graphite powder were gradually added into the mixture. The temperature was kept below $20^{\circ} \mathrm{C}$ under vigorous stirring using a mechanical stir bar for $2 \mathrm{~h}$. The temperature of the mixture was then increased and maintained at $35^{\circ} \mathrm{C}$. The mixture was continuously stirred for another $12 \mathrm{~h}$ until it turned into a brown paste. After that, $250 \mathrm{ml}$ of deionized water was added into the mixture and stirred for $30 \mathrm{~min}$. Next, $20 \mathrm{ml}$ of $35 \% \mathrm{H}_{2} \mathrm{O}_{2}$ and $800 \mathrm{ml}$ of deionized water were added into the mixture. The stir was continued until the mixture colour changed from brown into brilliant yellow. The mixture was filtered and washed using $1 \mathrm{M} \mathrm{HCl}$ and deionized water until the $\mathrm{pH}$ of the filtrate became neutral. Lastly, the mixture was dried in oven at $80^{\circ} \mathrm{C}$.

\subsection{Chemical reduction of GO nanosheet}

The RGO nanosheet was synthesized through chemical reduction of exfoliated GO nanosheet according to our previous report. ${ }^{17}$ Firstly, $200 \mathrm{mg}$ of solid GO was dispersed in $200 \mathrm{ml}$ of deionized water under ultra-sonication for $3 \mathrm{~h}$ by using a high-power ultrasonic pole at $0^{\circ} \mathrm{C}$ until it turned into a dark-brown GO aqueous colloid. In typical reduction process from $\mathrm{GO}$ to $\mathrm{RGO}, 100 \mathrm{ml}$ of $\mathrm{GO}$ colloid was mixed with $40 \mathrm{ml}$ of sodium oxalate solution $(0.45 \mathrm{M})$ in a $250 \mathrm{ml}$ conical flask under vigorous stirring. The final solution was kept at $\pm 95^{\circ} \mathrm{C}$ for a period of $1 / 2 \mathrm{~h}$ (RGO-1), $1 \mathrm{~h}$ (RGO2) and $2 \mathrm{~h}$ (RGO-3). Then, the products were centrifuged for $20 \mathrm{~min}$ at 3000-4000 rpm and washed using deionized water repeatedly. Finally, the products were dried at $80^{\circ} \mathrm{C}$ in oven.

\subsection{Characterization}

The FTIR spectra of the samples were obtained using Nicolet 5700 FTIR in the wavelength range of $500-4000 \mathrm{~cm}^{-1}$. The ultraviolet-visible spectra were obtained using Shimadzu UV-visible spectrophotometer (UV-1601 PC) with wavelength of 200-600 $\mathrm{nm}$. The morphology of the synthesized GO and RGO were characterized by HRTEM (FEI TECNAI G2) at acceleration voltage of $200 \mathrm{kV}$ and scanning electron microscopy (SEM, HITACHI TM3000). Thermogravimetric analysis (TGA) was conducted on a Mettler Toledo TGA/SDTA 851 thermal analyzer in a dynamic atmosphere of nitrogen. The samples were heated inside alumina crucible at $10^{\circ} \mathrm{C} \mathrm{min}{ }^{-1} \cdot{ }^{13} \mathrm{C} \mathrm{NMR}(400 \mathrm{MHz})$ spectra were collected using a Bruker Avance III HD. The electrical conductivity of samples was calculated from the $I-V$ characteristics by the four-point probe method. From the $I-V$ characteristics by the four-point probe method, the resistance of the samples was calculated according to Ohm's law. Therefore, the resistance, resistivity and conductivity of the samples were calculated using the following formula as reported by Sahoo et al: 19

$$
\begin{aligned}
& \text { Resistance }=V / I, \\
& \text { Resistivity }(\rho, \Omega \mathrm{cm})=\pi t / \ln 2(V / I), \\
& \text { Conductivity }\left(\sigma, \mathrm{S} \mathrm{cm}^{-1}\right)=1 / \rho,
\end{aligned}
$$

where $V$ is the measured voltage, $I$ the current applied and $t$ the thickness of the sample.

\section{Results and discussions}

\subsection{Plausible reduction mechanism}

The possible mechanisms for the reduction of carboxyl and epoxide groups of GO nanosheets using sodium oxalate as the reducing agent have been well established in this study. ${ }^{20}$ In case of carboxyl groups, the reduction mechanism involves the decarboxylation process which causes the liberation of carbon dioxide $\left(\mathrm{CO}_{2}\right)$ under heat treatment as shown in figure 1a. The mechanism of ring opening of epoxide groups in GO is according to the base-catalysed reaction. Since the epoxide groups are very reactive, the strong bases and nucleophiles are necessary to attack and open epoxides which led to relieve the strain of the threemembered ring. In this case, the strong base and nucleophile is hydroxyl group. Figure $1 \mathrm{~b}$ shows the plausible mechanism of reductive cleavage of epoxide groups in GO with a few steps. 


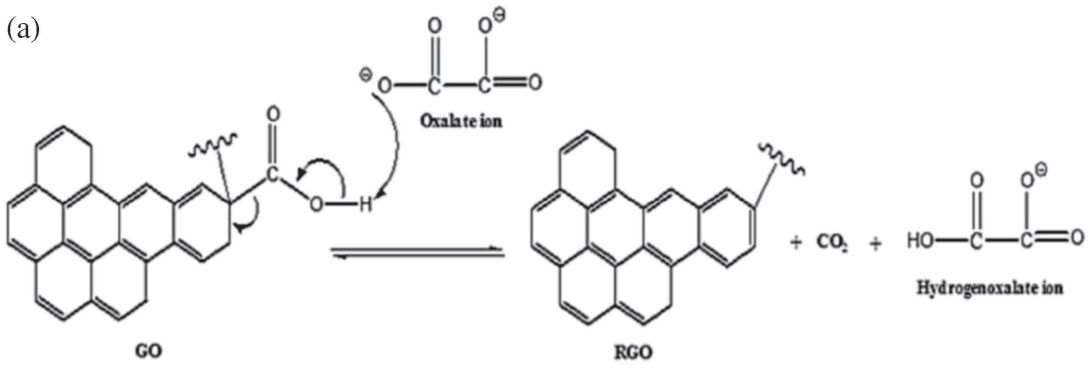

(b)

Step 1: Hydroxyl ion attacks and opens the epoxide ring to an alloxide

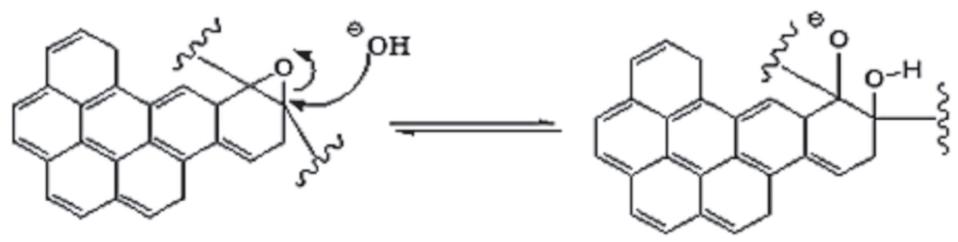

co

Step 2: Diolformation through the protonation of the alloxide

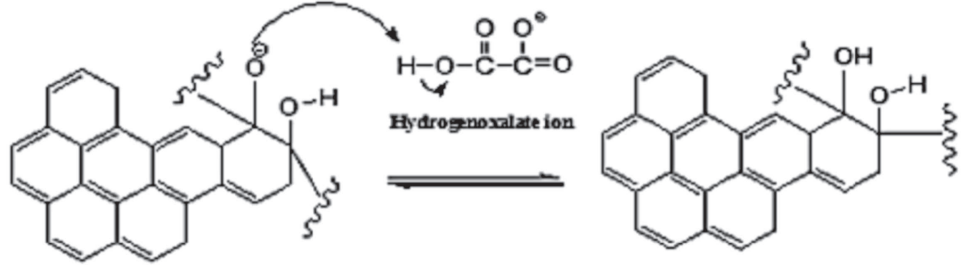

Step 3: Protonation of the oxalate ion

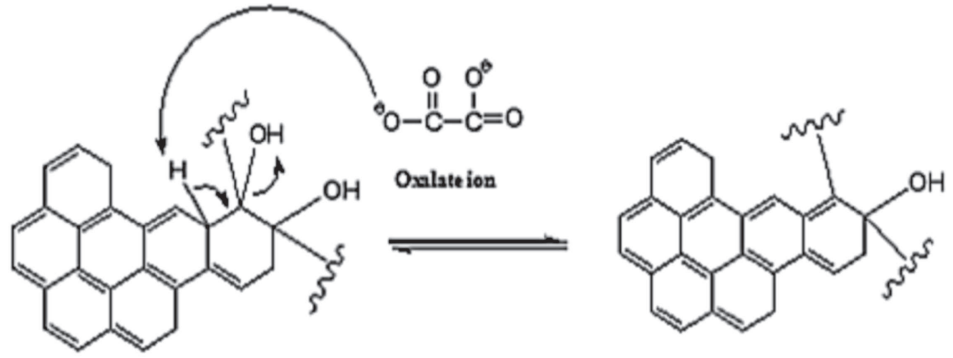

Step 4: Protomation of tydrogenoxabte ion to form RGO
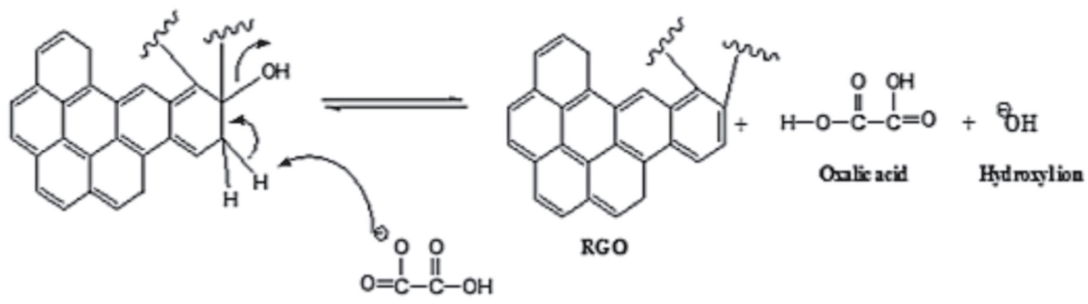

Hỵdrogenombtein

Figure 1. Plausible mechanism for the reduction of (a) carboxyl groups and (b) epoxide groups in GO using sodium oxalate as reducing agent.

\subsection{Structural analysis}

3.2a FTIR spectroscopy: FTIR analysis was performed to confirm the removal of oxygen-containing groups in the GO after being reduced by the sodium oxalate. Figure 2 shows the FTIR spectra for the GO, RGO-1, RGO-2 and RGO-3. The GO spectrum shows a broad peak at $3276 \mathrm{~cm}^{-1}$ and sharp peak at $1732 \mathrm{~cm}^{-1}$ which were attributed to 


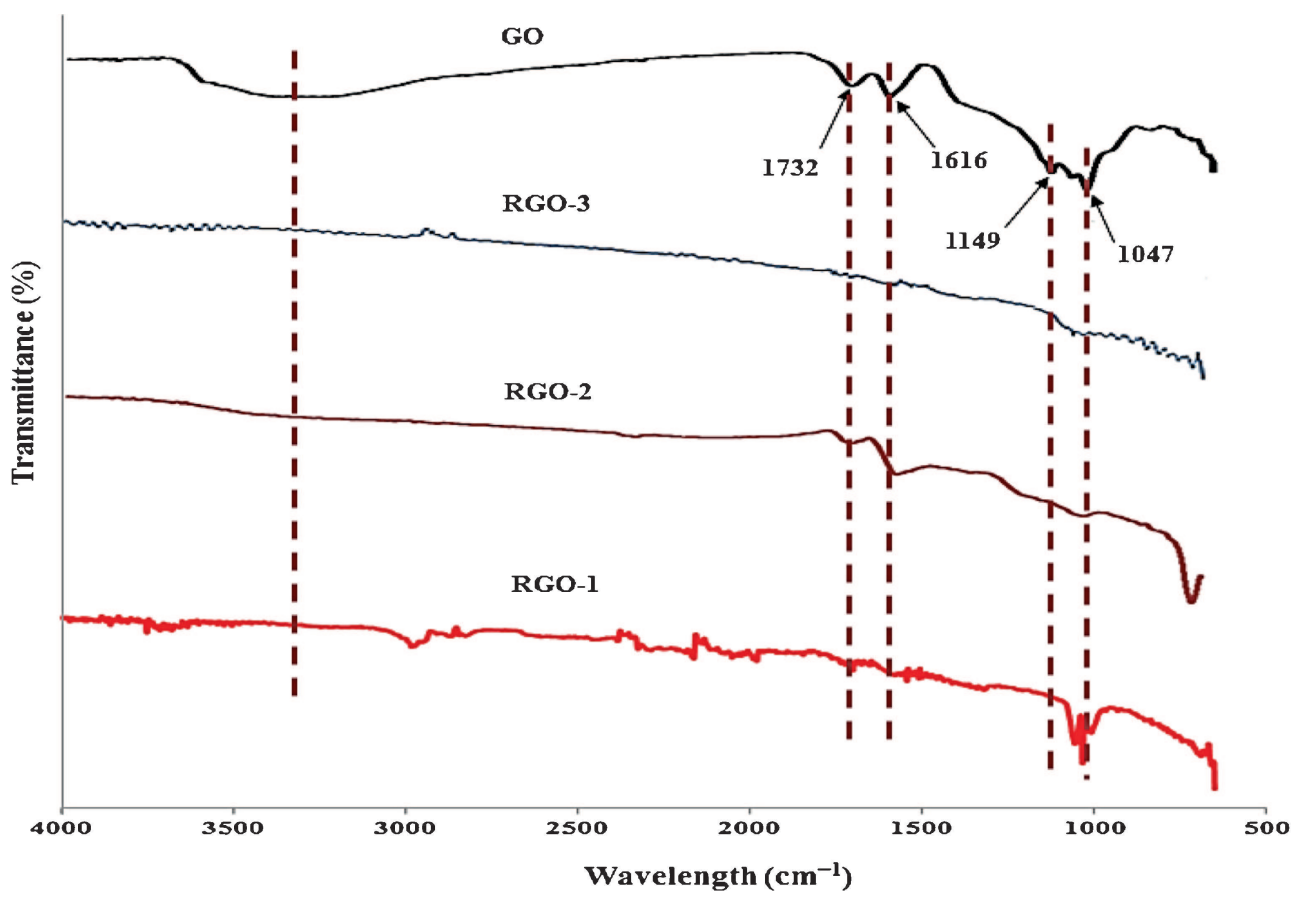

Figure 2. FTIR spectra for GO (before) and after being reduced by sodium oxalate for $30 \mathrm{~min}$ (RGO-1) $1 \mathrm{~h}$ (RGO-2) and $2 \mathrm{~h}$ (RGO-3).

the $\mathrm{O}-\mathrm{H}$ stretching and $\mathrm{C}=\mathrm{O}$ stretching vibration, respectively. Aromatic $\mathrm{C}=\mathrm{C}$ stretching vibration appearance was confirmed by a peak at $1616 \mathrm{~cm}^{-1}$. The peaks at 1149 and $1047 \mathrm{~cm}^{-1}$ were designated to epoxy $\mathrm{C}-\mathrm{O}$ stretching vibration and alkoxy $\mathrm{C}-\mathrm{O}$ stretching vibration, respectively; similar to the characteristic peaks as reported by Jin et al. ${ }^{11}$ Overall, the peak intensities were reduced remarkably with the reduction. After the reduction, the peak intensities for oxygen-containing group at 3276 and $1149 \mathrm{~cm}^{-1}$ were reduced remarkably, while the peaks at 1732 and $1047 \mathrm{~cm}^{-1}$ were significantly weakened for RGO-1 and RGO-2. The peaks at 3276, 1732, 1149 and $1047 \mathrm{~cm}^{-1}$ were totally disappeared for RGO-3. However, the peak at $1616 \mathrm{~cm}^{-1}$ was still available, which indicates that the $\mathrm{sp}^{2}$ hybridization of $\mathrm{C}=\mathrm{C}$ bonds have been well-restored. These results suggest that the GO nanosheets have been successfully reduced to RGO nanosheets using sodium oxalate as a chemical reducing agent when the reduction time is prolonged to a certain period.

3.2b UV-vis spectrophotometer: The UV-vis spectra for the GO, RGO-1, RGO-2 and RGO-3 are shown in figure 3. For the GO, there was a strong absorption peak at $230 \mathrm{~nm}$, corresponding to the conjugated aromatic double bonds $(\mathrm{C}=\mathrm{C})$ with $\pi-\pi^{*}$ transition. Another peak at $301 \mathrm{~nm}$, which was a shoulder band, corresponded to the carbonyl bonds $(\mathrm{C}=\mathrm{O})$ with $\mathrm{n}-\pi^{*}$ transition. After the reduction, a strong absorption peak appeared at around $\sim 242,249$, and $257 \mathrm{~nm}$ for RGO-1, RGO-2, and RGO-3, respectively. Thus, it indicates that the conjugated structure of RGO which is an aromatic $\mathrm{C}=\mathrm{C}$ bond is well restored upon reduction as similarly

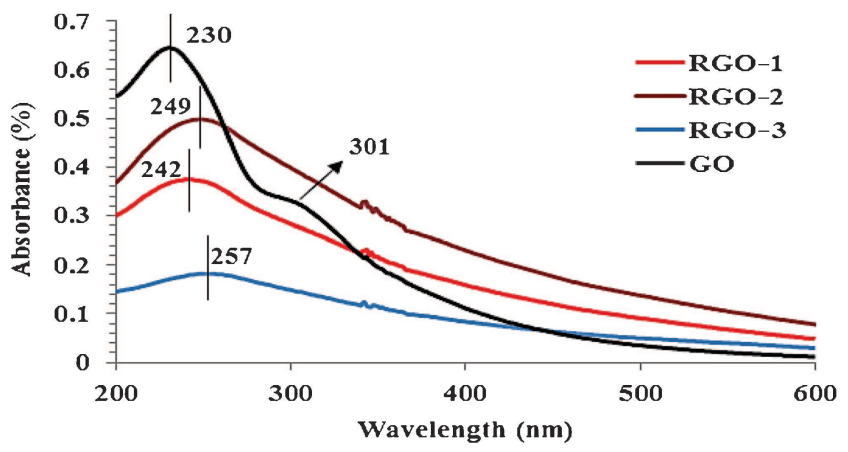

Figure 3. UV-vis absorption spectra of GO aqueous dispersion (before) and after being reduced by sodium oxalate for RGO-1, RGO-2 and RGO-3.

reported by Jin et al. ${ }^{11}$ This is in agreement with the FTIR results.

3.2c ${ }^{13} C$ NMR spectroscopy: The solid-state ${ }^{13} \mathrm{C}$ NMR spectra were carried out to characterize the reduction of GO by sodium oxalate. ${ }^{13} \mathrm{C}$ NMR spectra of GO and RGO3 are shown in figure $4 a$ and $b$, respectively. In the spectrum of GO, it was confirmed that the presence of abundant epoxide and hydroxyl groups that align perpendicular to the basal-plane carbon atoms at 66 and $73 \mathrm{ppm}$, respectively. There are too small peak of the carbonyl groups (carboxyl) for ${ }^{13} \mathrm{C}$ NMR detection, which are located at the edges of the basal plane. The resonance at $130 \mathrm{ppm}$ belongs to the un-oxidized $\mathrm{sp}^{2}$ carbons atom. In the spectrum of RGO-3, 

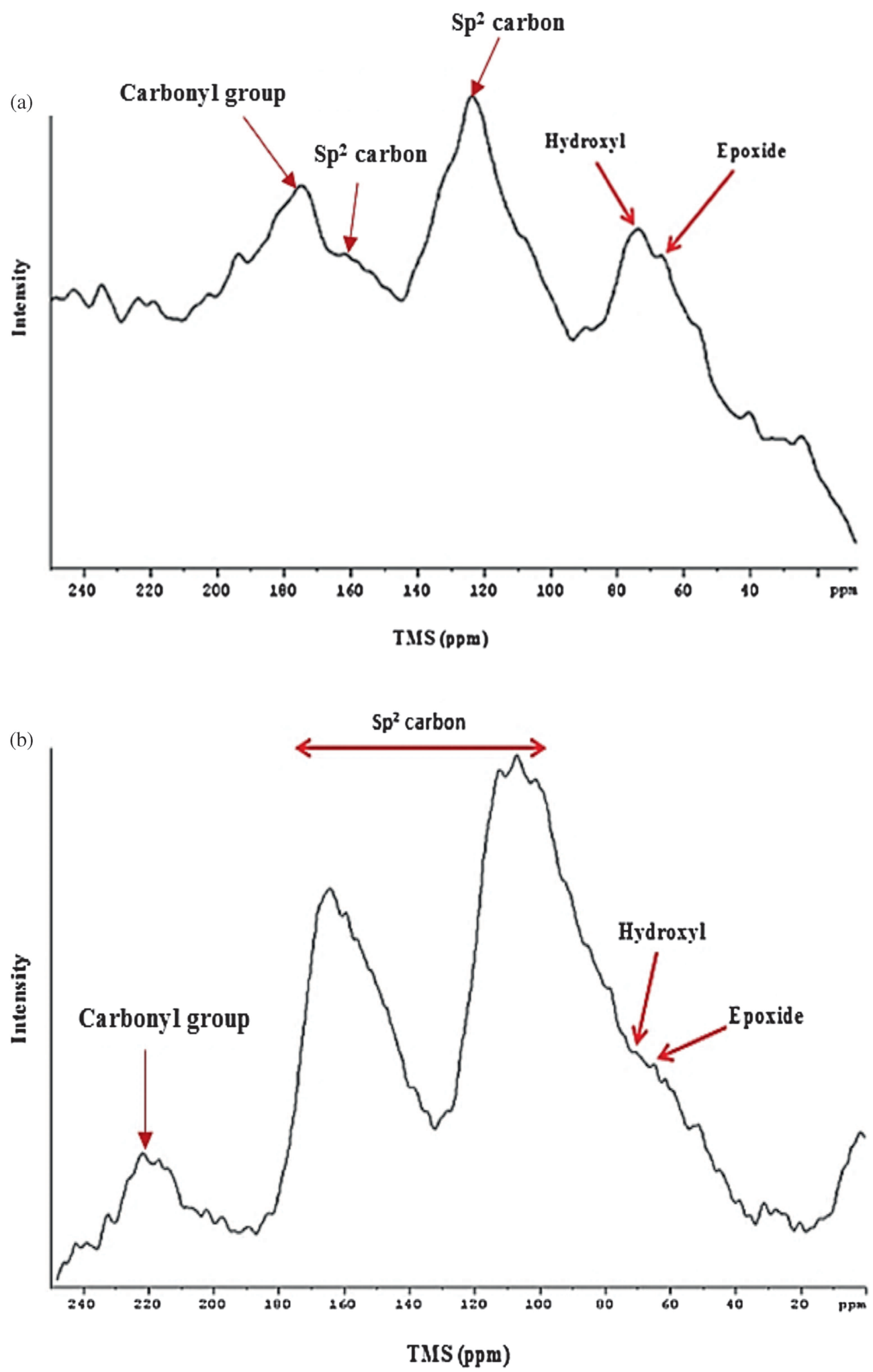

Figure 4. Solid-state ${ }^{13} \mathrm{C}$ NMR spectra of (a) GO and (b) RGO-3.

it indicates a significant reduction in the amount of epoxide and hydroxyl groups present with structural change after reduced by sodium oxalate. The peaks of those oxygencontaining functional groups became weaker and smaller. On the other hand, the peaks from the oxygenated and carbonyl carbons are totally reduced. In addition, the plentiful $\mathrm{sp}^{2}$ carbons atoms were introduced with the sharper peak in RGO-3 spectra, at around 90-160 ppm, suggesting the formation of graphene materials. ${ }^{21,22}$ RGO-3 has the high intensity of $\mathrm{sp}^{2}$ carbon network compared to GO. It indicates that the 
extensive conjugated carbon $\mathrm{sp}^{2}$ structure has been recovered in the reduction process.

\subsection{Morphological analysis}

The surface morphology of the GO and RGO-3 were investigated by using SEM and HRTEM. The surface morphology image of the GO is shown in figure 5a. It showed that a few layers of structure of GO nanosheets were corrugated. Figure $5 b$ shows the surface morphology of the RGO-3 which was observed in the top-view of SEM image. The RGO-3 was observed in figure $5 \mathrm{c}$ to have a wrinkled paperlike structure arranged in transparent layer and exhibits a very stable towards the radiation of electron emitted by high-energy electron beam. ${ }^{22}$ The number of the RGO layers can be identified through their folder edges. ${ }^{23}$ The HRTEM images that capture the border of the RGO-3 (figure 5d) showed almost a single layer as indicated by the arrow. Therefore, it was concluded that the produced RGO-3 was likely to be monolayer.

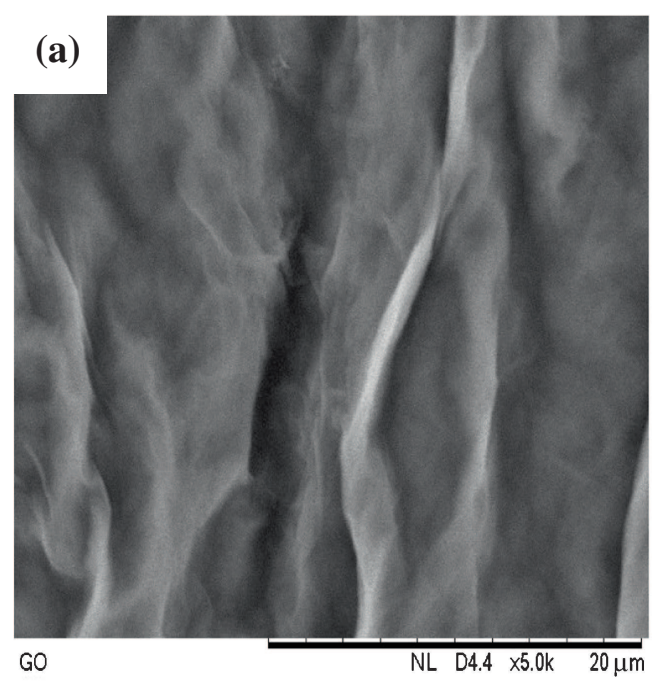

GO

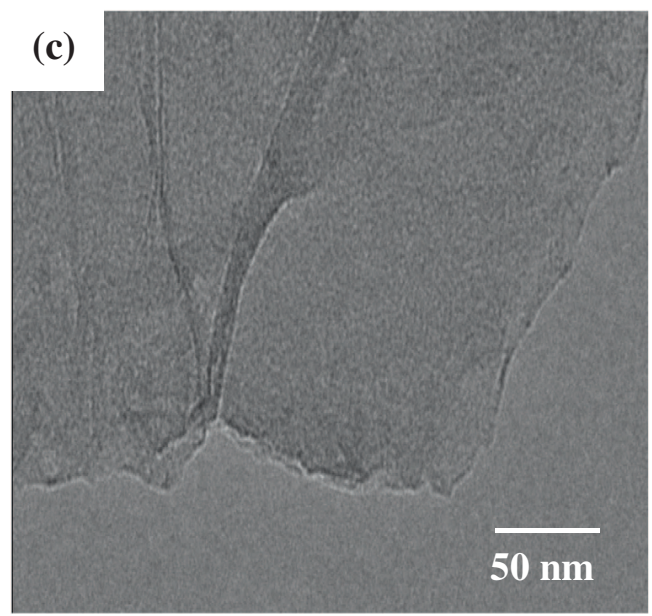

\subsection{Thermal stability analysis}

The effect of the reduction time on the thermal stability of the GO and RGO-3 were investigated by TGA analysis. The typical TGA curves of the GO and RGO-3 are shown in figure $6 \mathrm{a}$ and $\mathrm{b}$, respectively. The TGA curve of the GO exhibited two significant stages of mass loss upon the increase in temperature. The first stage of the mass loss was approximately $43 \mathrm{wt} \%$ at the temperature range of $0-300^{\circ} \mathrm{C}$, which is due to the loss of remaining oxygen-containing functional groups while the second stage at around $600^{\circ} \mathrm{C}$, displayed approximately $97 \mathrm{wt} \%$ mass loss which is related to the pyrolysis of the labile oxygen-containing functional groups as well as decomposition of carbon skeleton. In comparison with GO, significantly decreased mass loss was observed for RGO-3 and the TGA curves show a small weight loss in the temperature range from 0 to $600^{\circ} \mathrm{C}$ due to the efficient removal of oxygen-containing functional groups by using sodium oxalate as the reducing agent. At around $300^{\circ} \mathrm{C}$, the mass loss was about $22 \mathrm{wt} \%$ for RGO-3. At approximately $600^{\circ} \mathrm{C}$, the mass loss became more significant which

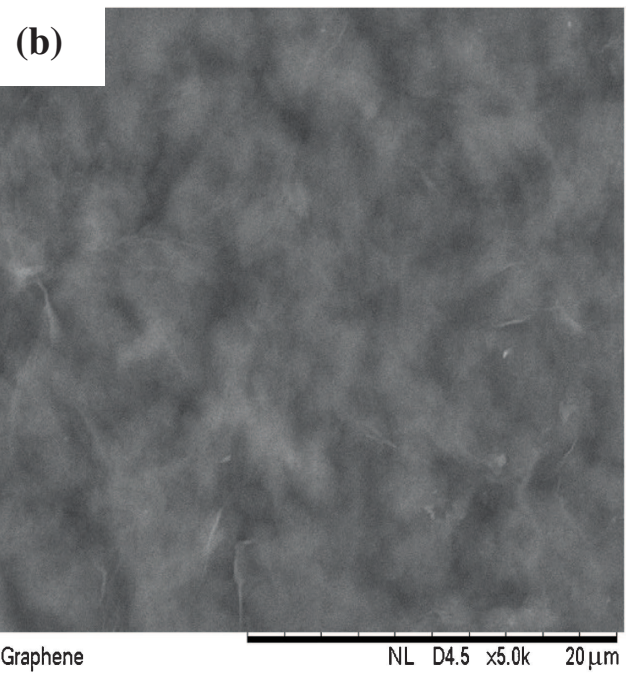

(d)

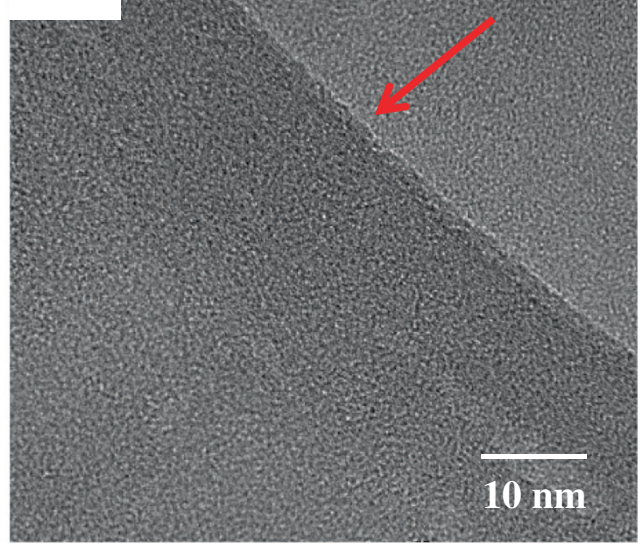

Figure 5. Surface morphology of (a) GO, (b) RGO-3 under scanning electron microscopy and HRTEM image of (c) RGO-3 and (d) RGO-3 edges at different magnifications. 


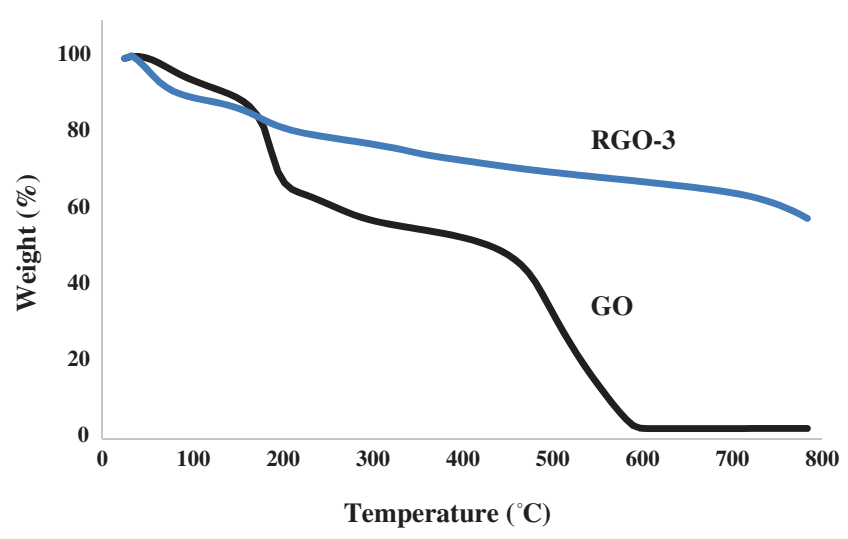

Figure 6. Comparison of thermal stability for (a) GO and (b) RGO-3 under TGA analysis.

was about $32 \mathrm{wt} \%$ for RGO-3. This suggests that the RGO3 exhibits greater thermal stability compared to GO due to the removal of labile oxygen-containing functional groups ${ }^{24}$ which leads to better graphitization and deoxygenation of RGO-3 with the enhanced van der Walls forces between layers. $^{11}$

\subsection{Electrical conductivity analysis (room temperature)}

Electrical conductivity $(\sigma)$ of RGO is the most critical criteria to evaluate the reduction degree and it is governed by its structural properties. In the present work, the conductivity improves with the increase of reduction time. This is due to the removal of the residual oxygen in the RGOs. In our case, the highest value of electrical conductivity was exhibited by RGO-3, which is about $\sim 2.0 \times 10^{3} \mathrm{~S} \mathrm{~m}^{-1}$ compared to RGO-2 and RGO-1. However, GO is an electrically insulating material since most of the carbon atoms in $\mathrm{GO}$ are $\mathrm{sp}^{3}$ hybridized. The existence of many oxygen-containing functional groups breaks the conjugated structure and thus resulting in a decrease of carrier mobility and concentration. The obtained value of electrical conductivity of RGO-3 using sodium oxalate as reducing agent is comparable with that of some other conventional reducing agent like $\mathrm{NaBH}_{4}\left(0.45 \mathrm{~S} \mathrm{~cm}^{-1}\right),{ }^{25}$ hydrazine $(22.4 \mathrm{~S}$ $\left.\mathrm{cm}^{-1}\right),{ }^{21}$ nascent hydrogen $\left(11.20 \mathrm{~S} \mathrm{~cm}^{-1}\right)^{26}$ and sodium carbonate $\left(10 \mathrm{~S} \mathrm{~m}^{-1}\right) .{ }^{11}$ Therefore, it was concluded that the reduction of GO with sodium oxalate can lead to the restoration of electrical properties of the prepared RGO.

\section{Conclusion}

In this paper, the degree of reduction towards the physicochemical properties of RGO in terms of structural, thermal and electrical conductivity at different reduction times using sodium oxalate as reducing agent has been reported. The structural analysis confirmed the formation of highquality RGO-3 with the removal of oxygen-containing functional groups from the surface of GO. From TGA, RGO3 is found to be more thermally stable compared to GO. The plausible mechanism of reduction of GO to RGO using sodium oxalate has been well proposed. This produced RGO3 with high electrical conductivity could be valuable for the practical application as a novel Pt electro-catalyst support in the promising energy conversion system of DMFC. Our future work will describe about the anode platinumbased catalyst by incorporating the graphene nanosheets as the electro-catalyst support for DMFC application.

\section{Acknowledgements}

We would like to acknowledge the Ministry of Education Malaysia and Ministry of Science Technology and Innovation (MOSTI), for the financial support under Fundamental Research Grant scheme (Vot.R.J130000.7809.4F592) and Science fund Grant (Vot.R.J130000.7942.4S057), respectively. Special thanks to Madam Hamitul Asma Ghazali, Associate Prof Dr Farediah Ahmad and Prof Dr Mustaffa Shamsuddin for their assistance.

\section{References}

1. Aziz M, Halim F S A and Jaafar J 2014 J. Teknol. 6911

2. Zhang Y, Shu H, Chang G, Ji K, Oyama M, Liu X and He Y 2013 Electrochim. Acta 109570

3. Ji K, Chang G, Oyama M, Shang X, Liu X and He Y 2012 Electrochim. Acta 8584

4. Ma C, Liu W, Shi M, Lang X, Chu Y, Chen Z, Zhao D, Lin W and Hardacre C 2013 Electrochim. Acta 114133

5. Seger B and Kamat P V 2009 J. Phys. Chem. C 1137990

6. Qian Y, Wang C and Le Z-G 2011 Appl. Surf. Sci. 25710758

7. Zhang M, Xi J, Sun Q, Yan Z, Chen M and Jing J 2013 Int. J. Hydrogen Energy 3816402

8. Lee C, Wei X, Kysar J W and Hone J 2008 Science 321385

9. Service R F 2009 Science $\mathbf{3 2 4} 875$

10. Balandin A A, Ghosh S, Bao W, Calizo I, Teweldebrhan D, Miao F and Lau C N 2008 Nano Lett. 8902

11. Jin Y, Huang S, Zhang M, Jia M and Hu D 2013 Appl. Surf. Sci. 268541

12. Amarnath C A, Hong C E, Kim N H, Ku B-C, Kuila T and Lee J H 2011 Carbon 493497

13. Pham T A, Kim J S and Jeong Y T 2011 J. Colloids Surf. A: Physicochem. Eng. Aspects 384543

14. Ji Y, Liu Q, Cheng M, Lai L, Li Z, Peng Y and Yang Y 2013 J. Mater. Sci. Eng. C 333811

15. Zhang J, Yang H, Shen G, Cheng P, Zhang J and Guo S 2010 Chem. Commun. 461112

16. Gao J, Liu F, Liu Y, Ma N, Wang Z and Zhang X 2010 Chem. Mater. 222213

17. Hanifah M F R, Jaafar J, Aziz M, Ismail A F, Othman M H D, Rahman M A, Norddin M N A M, Yusof N and Salleh W N W 2015 Funct. Mater. Lett. 815500261 
18. Hanifah M F R, Jaafar J, Aziz M, Ismail A F, Rahman M and Othman M H D 2015 J. Teknol. (Sci. Eng.) 74195

19. Sahoo S, Dhibar S, Hatui G, Bhattacharya P and Das C K 2013 Polymer 541033

20. Wade L G Jr 2010 Organic chemistry (USA: Pearson Education) 7 th ed

21. Stankovich S, Dikin D A, Piner R D, Kohlhaas K A, Kleinhammes A, Jia Y, Wu Y, Nguyen S T and Ruoff R S 2007 Carbon 451558
22. Wang G, Yang J, Park J, Gou X, Wang B, Liu H and Yao J 2008 J. Phys. Chem. C 1128192

23. Liu P, Huang Y and Wang L 2013 Synth. Met. 16725

24. Mitra M, Chatterjee K, Kargupta K, Ganguly S and Banerjee D 2013 Diam. Relat. Mater. 3774

25. Shin H J, Kim K K, Benayad A et al 2009 Adv. Funct. Mater. 191987

26. Pham V H, Pham H D, Dang T T, Hur S H, Kim E J, Kong B S, Kim S and Chung J S 2012 J. Mater. Chem. 2210530 